\title{
Karbon Depolama Miktarlarının Zamansal Değişimi
}

\author{
Melih KOCAMAN ${ }^{1}$,Birsen DURKAYA $^{1 *}$ \\ 1* Bartın Üniversitesi, Orman Fakültesi, Orman Mühendisliği Bölümü, 74100, BARTIN
}

\section{Öz}

Bolu Orman Bölge Müdürlüğü, Aladağ Orman İşletme Müdürlüğü, Demirciler Orman İşletme Şefliği’nin ormanlarının 1986-1995 ve 2009-2018 yıllarına ait biyokütle ve karbon tutma kapasiteleri hesaplanmıştır. Ormanlarının biyokütle ve karbon depolama miktarları Allometrik Biyokütle Yöntemi (ABD) ve Biyokütle Genişletme Faktörü (BEF) yöntemine göre belirlenmiştir. ArcGIS sürüm $10.3^{\mathrm{TM}}$ ortamında haritalandırılmıştır. Planlama biriminde 1986-1995 Plan döneminde iğne yapraklı meşcerelerde ABD yöntemiyle 103,20 ton/ha karbon değeri belirlenirken, BEF yöntemiyle 92,18 ton/ha olarak belirlenmiştir. 2009-2018 plan döneminde ise yöntemler ABD yöntemi 127,63 ton/ha ve BEF yöntemi 122,43 ton/ha karbon hesabı çıkarmıştır. Geniş yapraklı ve karışık meşcere tiplerinde de paralel sonuçlar görülmüştür. Allometrik denklem yönteminde, ağaç türleri için, çapa bağlı geliştirilen denklemler kullanıldığından diğer yönteme göre daha sonuçlar verdiği düşünülmektedir.

Anahtar Kelimeler: Allometrik denklem, BEF, karbon depolama, küresel ısınma.

\section{Temporal Variation of Carbon Storage Quantities}

\begin{abstract}
The biomass and carbon stock capacities of Bolu Forest Regional Directorate, Aladağ Forest Management Directorate, Demirciler Forest Management Directorate's forests between 1986-1995 and 2009-2018 were calculated. Biomass and carbon storage amounts of forests were determined according to Allometric Biomass Method (USA) and Biomass Expansion Factor (BEF) method. It is mapped to the ArcGIS ${ }^{\mathrm{TM}} 10.3$ environment. While the carbon value of 103.20 ton/ha was determined by the US method in the coniferous stands during the 1986-1995 Plan period, it was determined as 92.18 ton/ha by the BEF method. In the 2009-2018 plan period, 127.63 tons/ha of carbon was calculated with the US method and 122.43 tons /ha of carbon with the BEF method. Parallel results were also seen in broad leaf and mixed stand types.In the allometric equation method, since the equations developed based on the diameter are used for tree species, it is thought to give more results than the other method.
\end{abstract}

Keywords: Allometric equation, BEF, carbon stock, global warming.

\footnotetext{
*Sorumlu Yazar (Corresponding Author):

Birsen DURKAYA (Dr.); Bartın Üniversitesi, Orman Fakültesi, Orman Mühendisliği

Geliş (Received) : :05.03.2020

Bölümü, 74100, Bartın-Türkiye. Tel: +90 (378) 2235173

E-mail: bdurkaya@bartin.edu.tr ORCID: 0000-0002-3132-7044 


\section{Giriş}

Doğal kaynaklara artan talepler karşılanırken kaynakların bilinçsiz kullanılması biyoçeşitliliğin tahribine (Olalekan vd., 2019; Dhakal vd., 2019), kurak mıntıkalarda su kaynaklarının yönetilmesinde sorunlara (Leonard vd., 2019), arazi kullanım değişikliklerinin orman ekosistemlerinin tahribine kadar ulaşması küresel iklim değişimine sebep olmaktadır (Fearnside, 1985). Küresel iklim değişiminin en büyük nedenlerinden birisi sera gazlarının özellikle de atmosferde çok küçük bir yüzdelerde bulunan atmosferik karbondioksitin (CO2), giderek sınır değerini aşmasıdır (UN, 1992; Vashum ve Jayakumer, 2012; IPCC, 2013). Yapılan çalışmalar bu ilişkinin varlığını açıklamaktadır (Matthews ve ark. 2009; Zickfeld, 2009;Tosarka et.all., 2016; Matthews vd.,2018). Sera gazı (GHG) emisyonlarını azaltma ve öngörülen iklim değișikliklerini durağanlaștırma çabaları içerisinde orman alanları karbon havuzu olarak önemli görülmektedir (Baker vd., 2019). Karbon havuzu olan ormanlar, karasal ekosistemler içerisinde \%75-80 depolama oranıyla küresel ısınmanın etkilerinin azaltılması ve geciktirilmesinde önemli etkiye sahiptir (Woodwell vd., 1978; Hashimotio vd., 2000; Jandl vd., 2007). Karbon bağlama ve uzun yıllar depolama kabiliyeti nedeniyle diğer karasal ekosistemlerden (Çayır-mera-ziraat gibi) daha değerli görülmektedir.

Arazi Kullanımı, Arazi Kullanımı Değişimi ve Ormancılık İçin İyi Uygulama Rehberinde (Good Practise Guidance for LULUCF) objektif ve uygun yöntemler kullanılarak, ülkelerin karbon stok değişimi hesaplamalarının yapılması istenmektedir. Ayrıca belirlenen değişikliklerin zaman içerisinde azaltılması yönünde önlemlerin alınmasını öngörmektedir (IPCC, 2003). Bu sebeplerle, orman karbon stoklarının doğru ve eksiksiz olarak belirlenebilmesine yönelik artan bir ilgi vardır (Brown, 2002; Chave vd., 2005; Schulp vd., 2008; Durkaya vd., 2013a).

Orman alanlarının karbon depolama kapasitelerinin ve karbon depolamasındaki değişimlerin belirlenmesinde orman biyokütlesinden yararlanılmaktadır. Bir bireyin biyokütlesinde biriken karbon miktarı ile bütün orman alanındaki karbon miktarını elde etmek mümkündür (Backéus vd., 2005). IPCC ise karbon stok değişimlerinin belirlenmesinde orman envanterinin kullanılmasını gerektiren yöntemi önermektedir. Ancak orman envanterleri odun hacmine odaklanmakta, biyokütle hesaplamaya yönelik verileri bulundurmamaktadır (Coomes, vd., 2002; Durkaya vd., 2013b). Orman envanterine dayalı bir karbon hesabı yapılırsa Biyokütle Genişletme Faktörleri (Biomass Expansion Factors (BEF) kullanılarak dikili gövde hacminden toprak üstü ve altı karbon değerleri hesaplanmaktadır. Yeterli veri olması durumunda ağaç türleri için ayrı ayrı geliştirilen ve bölgelere ait Allometrik Biyokütle Denklemleri (ABD) kullanılmaktadır (Schroeder vd., 1997; Van Camp vd., 2004; Usuga vd., 2010; Durkaya vd., 2014; Gençay vd., 2018).

\section{Allometrik Biyokütle Denklemleri (ABD) Yöntemi}

Bitkinin kolay ölçülen değerlerinden biyokütle gibi daha zor belirlenen değerlere ulaşmasını kolaylaştıran ilişki allometridir (Huxley, 1993; Gower vd., 1999; Niklas ve Enquist, 2001; Niklas vd., 2005). Bu ilişkiyi matematiksel olarak gösteren denklemler Allometrik Biyokütle Denklemleri olup (Kangas ve Maltamo 2006; Shi ve Liu, 2017) yüksek doğruluk sebebiyle (Chave vd., 2014; Paul vd., 2016) tercih edilmektedir. ABD’de en fazla kullanılan parametreler göğüs çapı ve ağaç boyu değişkenleridir, ancak göğüs çapı ağaç boyuna kıyasla daha kolay ölçüldüğü ve hata payının daha düşük olması sebebiyle daha fazla kabul görmüş bir değişkendir (Wang, 2006; Porté vd., 2002). Her ağacın fiziksel yapısı ve yoğunluğu farklı olduğundan her ağaç türü için ayrı ayrı ABD geliştirilmelidir (Ketterings vd., 2001). Türkiye'de bugüne kadar yapılan biyokütle ve karbon çalışmaları gelişmiş ülkelere kıyasla daha kısıtlı olup, pek çok ağaç türü için henüz ABD'leri düzenlenmemiştir.

\section{Biyokütle Genişletme Faktörü (BEF) Yöntemi}

Ormanlarının gelişimini izlemek ve değerlendirmek amacıyla ulusal orman envanterleri düzenlenmektedir. Ulusal orman envanteri verileri kullanılarak toprak üstü biyokütleyi belirlemek, ormanda büyüyen hacim ile biyokütlenin ilişkili olduğu varsayımına dayanmaktadır (Schroeder vd., 1997; Fang vd., 2007; Shi ve Liu, 2017). Envanter verilerinden ağaç servetine dayalı olarak biyokütle belirleme Biyokütle Genișletme Faktörü ya da uluslararası kabul gören ismiyle Biomass Expension Factor (BEF) yöntemidir. Bu yöntemde ağaç servetinin BEF katsayısı odun yoğunluk değeri ile çarpımı sonucu toprak üstü biyokütle değerine ulaşılmaktadır. Odun yoğunluk değeri, fırın kurusu ağırlık değerinin yeşil haldeki hacim değerine oranıdır (Dewar and Cannell 1992; Porte vd., 2002; Fukuda vd., 2003; Tobin ve Nieuwenhuis, 2007). Daha sonra ise kök/sak oranı kullanılarak toprak üstü biyokütleden toprak altı biyokütleye dönüşüm yapılmaktadır.

Uygun karbon dönüştürme katsayısı toplam biyokütle ile çarpılarak servette biriken karbon miktarı belirlenmektedir (IPCC, 2003; Tolunay ve Çömez, 2008; Durkaya vd., 2014). BEF değerleri, dikili servetleri ağaç kısımlarında da biriken biyokütleye dönüştüren genişletme faktörü olarak tanımlamaktadır (Milne vd., 1998; Schoene, 2002; IPCC, 2003; 2006; Somogyi vd., 2007; Tobin ve Nieuwenhuis, 2007; Pajtík vd., 2008). 
BEF’ler sabit olmayıp, meşcere yaşına, sıklığına, bonitet derecesine ve ağaç türüne göre değişkenlik göstermektedir (Schroeder vd., 1997; Fang vd., 1998; Brown vd., 2002).

LULUCF kılavuzunda, orman ekosistemindeki canlı biyokütleye ait karbon havuzlarında yıllık karbon stok değişimlerini hesaplamak için katsayılar belirlenmiştir. Türkiye ormanlarındaki karbon stok değişimlerinin GPG-LULUCF kılavuzuna uygun olarak hesaplanması sırasında kullanılacak katsayılar önerilmiştir (FRA, 2010; Yolasığmaz vd., 2016). FRA-2010 kılavuzunda eşitliklerde kullanılan katsayılar için her ülkenin kendi değerlerini kullanması önerilmektedir, çünkü her ülkenin enlem-boylam ve iklim kuşaklarına göre ormanlarının gelişimi farklılaşmaktadır Türkiye ormanlarında kullanılmak üzere önerilen ilk katsayılar Asan (1995; 2002) tarafından geliştirilmiştir. Türkiye orman alanlarının biyokütle ve karbon hesaplamaları 2008 yılından itibaren Ekosistem Tabanlı Fonksiyonel Orman Amenajman Planlarında (ETFOP) önerilen yöntem kullanılarak yapılmaktadır. ETFOP'un Düzenlenmesine Ait Usul ve Esaslar (2014) kapsamında, Tolunay $(2011,2012)$ ile Tolunay ve Çömez (2008) tarafından FRA 2010 esas alınarak geliştirilen BEF katsayıları kullanılmaktadır (Tablo 1). Bu çalışmada ETFOP tarafindan önerilen BEF katsayıları kullanılmıştır (OGM, 2014).

Tablo 1. ETFOP yönetmeliğindeki BEF formül ve katsayıları.

\begin{tabular}{llll}
\hline & $\begin{array}{l}\text { İğne Yapraklı } \\
\text { Orman }\end{array}$ & $\begin{array}{l}\text { Geniş Yapraklı } \\
\text { Orman }\end{array}$ & Bozuk Orman \\
\hline Toprak Üstü Biyokütle (TÜB) & ${ }^{*}$ DGHx0,446x1,212 & ${ }^{*}$ DGHx0,541x1,3 & ${ }^{*}$ DGHx0,446x1,212 \\
Toprak Üstü Karbon (TÜK) & TÜB x 0,51 & TÜB x 0,48 & TÜB x 0,51 \\
Toprak Altı Biyokütle (TAB) & TÜB x 0,29 & TÜB x 0,24 & TÜB x 0,40 \\
Toprak Altı Karbon (TAK) & TAB x 0,51 & TAB x 0,48 & TAB x 0,51 \\
Ölü Odundaki Karbon (ÖOK) & TÜB x 0,01 x 0,47 & TÜB x 0,01 x 0,47 & TÜB x 0,01 x 0,47 \\
Ölü Örtüdeki Karbon (ÖÖK) & Alan x 7,46 & Alan x 3,75 & Alan x 1,86 \\
Topraktaki Karbon & Alan x 76,56 & Alan x 84,82 & Alan x 19,14 \\
\hline TOPLAM KARBON & TÜK + TAK + ÖOK + ÖÖK + Topraktaki Karbon \\
\hline
\end{tabular}

* Dikili Gövde Hacmi (DGH).

\section{Materyal ve Metot}

Bu çalışmanın konusunu Bolu Orman Bölge Müdürlüğü (OBM), Aladağ Orman İşletme Müdürlüğü’ne (OİM) bağlı Demirciler Orman İşletme Şefliği (OİŞ) meşcerelerinin karbon depolama kapasitelerinin Allometrik Biyokütle Denklemleri (ABD) ve Biyokütle Genişletme Faktörleri (BEF) yardımıyla belirlenmesi ve kıyaslanmasının incelenmesi oluşturmaktadır.

Çalışma materyali olarak Demirciler (OİŞ)'ne ait 1986-1995 ve 2009-2018 dönemlerine ait orman amenajman planları kullanılmıştır. Amenajman planlarının Meşcere Tipleri Tanıtım Tablosundaki, meşcere tiplerinde ki her ağaç türünün çap sınıflarındaki ağaç sayıları ve o çap sınıfının orta çap değerlerinden ABD metodu ile hesaplama yapmak için yararlanılmıştır. Aynı zamanda BEF metodu için Meçcere Tipleri Tanıtım Tablosundaki meşcere tiplerinin servetlerinden faydalanılmıştır.

\section{1. Çalışma Alanının Tanıtımı}

Demirciler Orman İşletme Şefliği, ilk defa 1964-1973 ve 1968-1977 yılları arası için düzenlenen planlarla işletilmiştir. Daha sonra 1980- 1989 yılları arasında sadece Göknar işletme sınıfı için Erencik Doruğu adıyla plan yenilemesi yapılmıştır. Bunu devam eden 1986-1995 dönemi amenajman planı, 2 yıllık avans planları, 19992008 dönemi ve 2009-2018 döneminde amenajman planları ile işletilmiştir. Çalışma alanı Greenwich başlangıç meridyenine göre: $31^{\circ} 36^{\prime} 55^{\prime \prime}-31^{\circ} 46^{\prime} 32^{\prime \prime}$ doğu boylamları ile $40^{\circ} 38^{\prime} 08^{\prime \prime}-40^{\circ} 45^{\prime}$ 06" kuzey enlemleri arasındadır. Ayrıca işletme şefliği 1/25.000 ölçekli G27b4, G27a3, G27d1, G27d2, G27c1 no’lu memleket paftalarında yer almaktadır (Şekil 1.). 


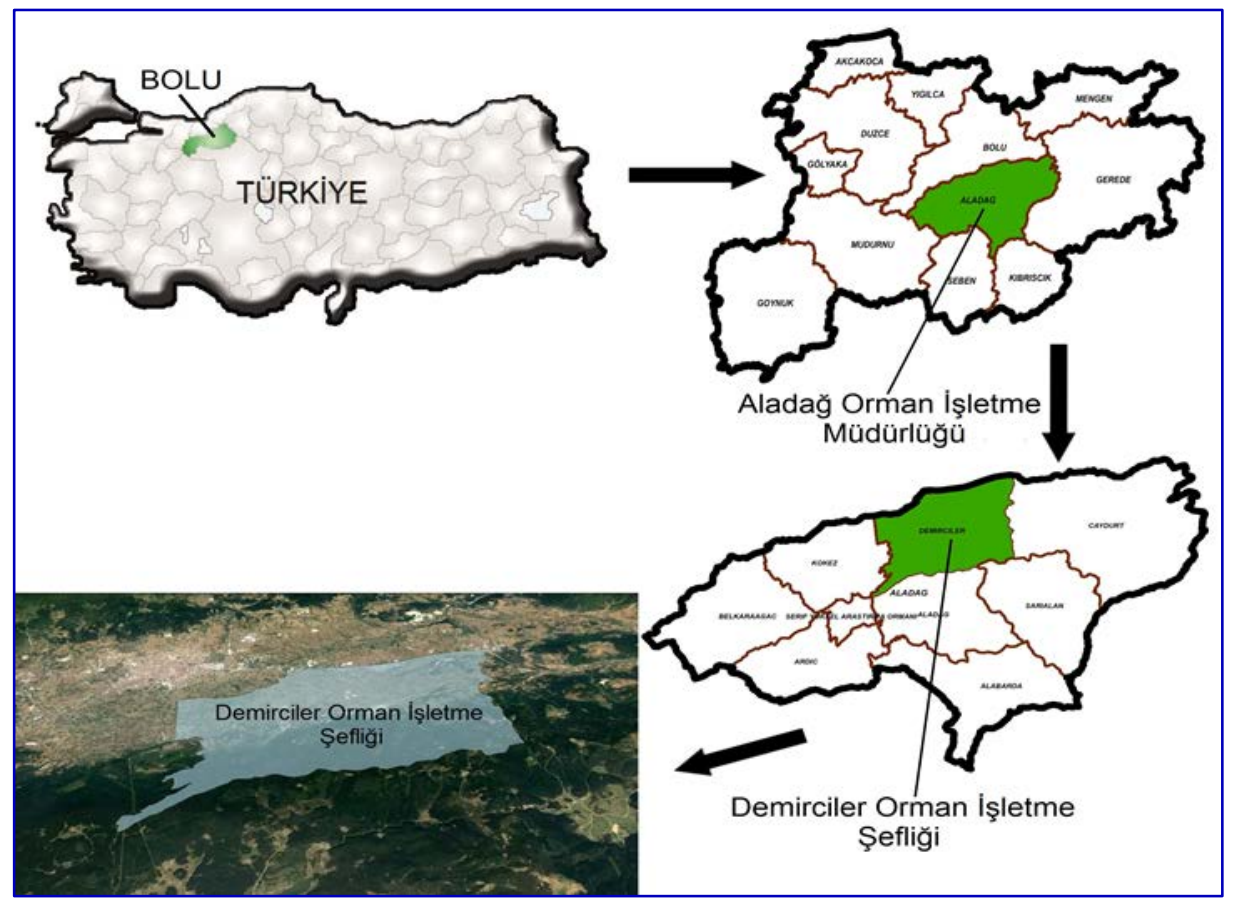

Şekil 1: Demirciler Orman İşletme Şefliği sınırları.

Alanın hâkim ağaç türleri Göknar, Karaçam, Sarıçam, Kayın, Meşe, Gürgen ve diğer yapraklılardan olup, saf ve karışık meşcereler olușturmaktadırlar. 1986-1995 orman amenajman planlarında verimli orman sahası 3.627 ha (iğne yapraklı meşcere 2.972,5; geniş yapraklı meşcere 457; karışık meşcere 198 ha), bozuk orman sahası 1.386 ha, ormansız alanların toplamı ise 5.527 ha olarak belirtilmiştir (Anon, 1986).

2009-2028 plan döneminde ise verimli orman sahası 4.485 ha (iğne yapraklı meşcere 2.089,6, geniş yapraklı 682,1 , karışı meşcere 1.713,8 ha), bozuk orman sahası 702,4 ha, ormansız sahalar toplamı ise 5268.9 ha'dır (Anon, 2009).

\subsection{Metod}

Bu çalışma Bolu Orman Bölge Müdürlüğü Aladağ İşsletme Müdürlüğü’ne ait Demirciler OİŞ’nin meşcerelerinin karbon depolama kapasitelerini tespit edip birbirleri ile kıyaslamak amacıyla yapılmışıtır. Biyokütle ve karbon miktarları, ABD ve BEF katsayıları kullanılarak iki ayrı şekilde belirlenmiştir. Her iki yöntemin uygulanması ilgili amenajman planları kullanılarak gerçekleştirilmiştir. Çalışmada kullanılan göğüs yüksekliği çapı $\left(\mathrm{d}_{1,30}\right)$, dikili ağaç serveti değerleri ve meşcere tiplerine ait veriler ilgili orman amenajman planlarından alınmıştır. ArcGIS ${ }^{\text {TM }}$ sürüm 10.3 programı kullanılarak sayısal olmayan 1986-1995 meşcere tipleri haritası sayısallaştırılmış, 2009-2018 yılına ait meşcere tipleri haritası sayısal mevcut haliyle ilgili birimden temin edilerek kullanılmıştır.

\section{ABD Yöntemiyle Biyokütle ve Karbonun Hesaplanması}

Çalışmada meşcere tanıtım tipleri tablolarında mevcut olan her ağaç türü için, çap sınıfı ortasına denk gelen çaptaki bir ağacın toprak üstü tüm ağaç biyokütle değerleri hesaplanmıştır. Bu amaçla Tablo 2'deki ABD’leri kullanılmıştır. İlgili meşcere tipinde her tür için çap sınıfındaki ağaç sayıları ile belirlenen biyokütle miktarı çarpılmış ve tüm çap sınıflarının toplamı elde edilmiştir. Meşcere tipinde bulunan tüm ağaç türleri birlikte değerlendirilerek meşcere tipinin hektardaki biyokütlesine ulaşılmıştır.

Biyokütle denklemleri olmayan türlerin biyokütle hesabında biyokütle denklemi mevcut olan iğne yapraklı ve geniş yapraklı türlerin çaplara göre verdiği biyokütle miktarlarının ortalaması kullanılmıştır. Toprak altı biyokütle miktarının belirlenmesine yönelik yeterli biyokütle modelleri bulunmadığından, toprak altı biyokütle miktarları BEF yöntemindeki iğne yapraklılar için 0,29, geniş yapraklılar için 0,24 katsayıları kullanılarak hesaplanmıştır (Tablo 2). 
Tablo 2. Ağaç türleri için geliştirilen ABD’ler.

\begin{tabular}{|c|c|c|}
\hline Ağaç Türü & $\begin{array}{l}\text { Allometrik Biyokütle Denklemleri } \\
\text { (TAB=Tüm Ağaç Biyokütle) }\end{array}$ & Kaynak \\
\hline $\begin{array}{l}\text { Pinus brutia Ten. } \\
\text { Pinus nigra Arnold. } \\
\text { Pinus sylvestris L. } \\
\text { Cedrus libani L. } \\
\text { Abies } \\
\text { bornmulleriana Matf. } \\
\text { Quercus sp. } \\
\text { Fagus orientalis Lipsky. } \\
\text { Castanea sativa Mill. }\end{array}$ & $\begin{array}{l}\text { TAB }=-1.92352+2.243357 \ln (d) \\
\text { TAB }=-106.55+10.61818 d+0.100728 d^{2} \\
\text { TAB }=-26.11437+0.436421 d^{2} \\
\text { TAB }=-37.21449-8.0832 d+0.64481 d^{2} \\
\text { TAB }=-24.7765+0.525998 d^{2} \\
T A B=-302.193+26.56569 d \\
\log (T A)=2.8626+0.0124 d-14.9099 d^{-1} \\
\text { TAB }=-376.794+28.7981 d\end{array}$ & $\begin{array}{l}\text { Durkaya vd., 2009a } \\
\text { Durkaya vd., 2009b } \\
\text { Durkaya vd., 2010 } \\
\text { Durkaya vd., 2013a } \\
\text { Durkaya vd., 2013b } \\
\text { Durkaya, } 1998 \\
\text { Saraçoğlu, } 1998 \\
\text { İkinci, } 2000\end{array}$ \\
\hline
\end{tabular}

Çalışmada toprak üstü ve toprak altı biyokütle değerlerinin yaklaşık \%50'sinin karbon olduğu varsayımından (Laiho and Laine, 1997; Elias and Potvin 2003; Lamlom and Savidge, 2003) hareketle 0,5 ile çarpılarak toplam karbon değerine ulaşılmıştır. Bozuk meşcereler için meşcere tanıtım tablolarında ağaç türlerine ait çap değerleri verilmediğinden yalnızca verimli orman alanları için hesaplamalar yapılmıştır.

\section{BEF Yöntemiyle Biyokütle ve Karbonun Hesaplanması}

Bu çalışmada ETFOP tarafından önerilen BEF katsayıları kullanılmıştır (Tablo 1). Bu amaçla meşcere tipleri bazında bulunan her ağaç türünün servetleri iğne yapraklıysa 0,446 ve 1,212, geniş yapraklıysa 0,541 ve 1,31 katsayıları ile çarpılarak toprak üstü biyokütle miktarları hesaplanmıştır. Toprak altı değerleri, toprak üstü biyokütle değerlerinin iğne yapraklı türler için 0,29, geniş yapraklı türler için 0,24 ile çarpılmasıyla belirlenmiştir. Toprak altı ve toprak üstü değerleri kullanılarak toplam biyokütle elde edilmiştir. Zhang vd. (2008) yaptıkları çalışmada biyokütlede depolanan karbonu hesaplamaları sonucunda karbonun tek ağaç firın kurusu ağırlığının ortalama \%49,9 olduğunu, türlere göre bu değerin \%43,7 ile \%55,6 arasında değiştiğini ortaya koymuşlardır. Lamlom ve Savigne (2003)'nin 41 türü kapsayan çalışmasında ise biyokütlenin \%46,3 ile \%55,2 arasında karbon stokladığını keza FRA-2010 Kılavuzunun 5.2 No'lu ek tablosunda Türkiye'nin bulunduğu coğrafi iklim zonu dikkate alındığına ortalama iğne yapraklı türlerde $\% 51$, geniş yapraklı türlerde ise $\% 48$ karbon stoklandığı hesaplanmıştır. Bu çalışmada toprak üstü, toprak altı ve toplam biyokütle değerlerini karbon miktarına dönüştürmek için geniş yapraklı türler 0,48 , iğne yapraklı türler ise 0,51 karbon dönüşüm katsayısı ile çarpılmıştır (IPCC 2006; Tolunay, 2011, Durkaya vd. 2017). Bozuk meşcereler için amenajman planlarının meşcere tanıtım tablolarında ağaç türlerine ait servet değerlerinin verilmesine karşılık, çap değerleri işlenmediğinden ABD yönteminde hesap yapılamayan biyokütle ve karbon, BEF yönteminde de hesaba katılmamıştır. Bu şekilde her iki yöntemde verimli orman alanları üzerinden kıyaslanmıştır.

\section{Karbon Depolama Kapasitesinin Haritalanması}

Çalışma alanı için; arazi kullanım tipi haritası, toprak üstü, toprak altı, toplam biyokütle ile karbon değerlerinde plan periyotlarında göre gözlenen değişimler, meşcere tipleri haritaları ve topoğrafik haritalardan yararlanılarak hazırlanmıştır.

Sayısal haritaları bulunmayan 1986-1995 dönemine ait meşcere tipleri haritaları ArcGIS ${ }^{\mathrm{TM}}$ sürüm 10.3 programında topoğrafik haritalar ve memleket haritaları referans alınarak rektifiye edildikten sonra sayısallaştırılma işlemine gerçekleştirilmiştir. Daha sonra orman amenajman planında bulunan meşcere tanıtım tablolarında ki hektardaki dikili servet, ağaç türlerinin miktarları, alan verileri bilgisayar ortamına aktarılmıştır. Hesaplanan biyokütle ve karbon depolama miktarları ArcGIS ${ }^{\mathrm{TM}}$ sürüm 10.3 programında ilgili dönemlere ait haritaların öznitelik tablolarına işlenerek karbon haritaları üretilmiştir.

\section{Bulgular ve Tartışma}

Demirciler OİŞ’deki alanların arazi kullanım değişimleri ile toprak üstü biyokütle ve karbon depolama konusundaki değişimler, amenajman planları verilerinden yararlanılarak incelenmiştir. Bulgular ABD ve BEF yöntemleri olmak üzere iki başlıkta ele alınmıştır. Çalışma alanına ait 1986-1995 ve 2009-2018 plan dönemi 
meşcere tiplerinden üretilen iğne yapraklı, geniş yapraklı ve bozuk ormanlar ile orman dışı alanların yayılışını gösteren haritalar Şekil 2 ve 3'te verilmiştir. 1986-1995 plan döneminde iğne yapraklı ormanlar 2.972,5 ha iken 2009-2018 plan döneminde 882,6 ha azalarak 2.089,6 ha’a düşmüştür. 1986-1995 plan döneminde geniş yapraklı ormanlar 457 ha iken 2009-2018 plan döneminde 225,1 ha artarak 682,1 ha’a çıkmıştır. 1986-1995 plan döneminde karışık ormanlar 198 ha iken 2009-2018 plan döneminde 1.515,8 artarak 1.713,8 ha’a çıkmıştır. 1986-1995 plan döneminde bozuk alanlar 1.386,0 ha iken 2009-2018 plan döneminde 683,6 ha azalarak 702,4 ha’a çıkmıştır. 1986-1995 plan döneminde orman dışı alanlar 5.527 ha iken 2009-2018 plan döneminde 339.1 ha azalarak 5.187,9 ha’a düşmüştür.

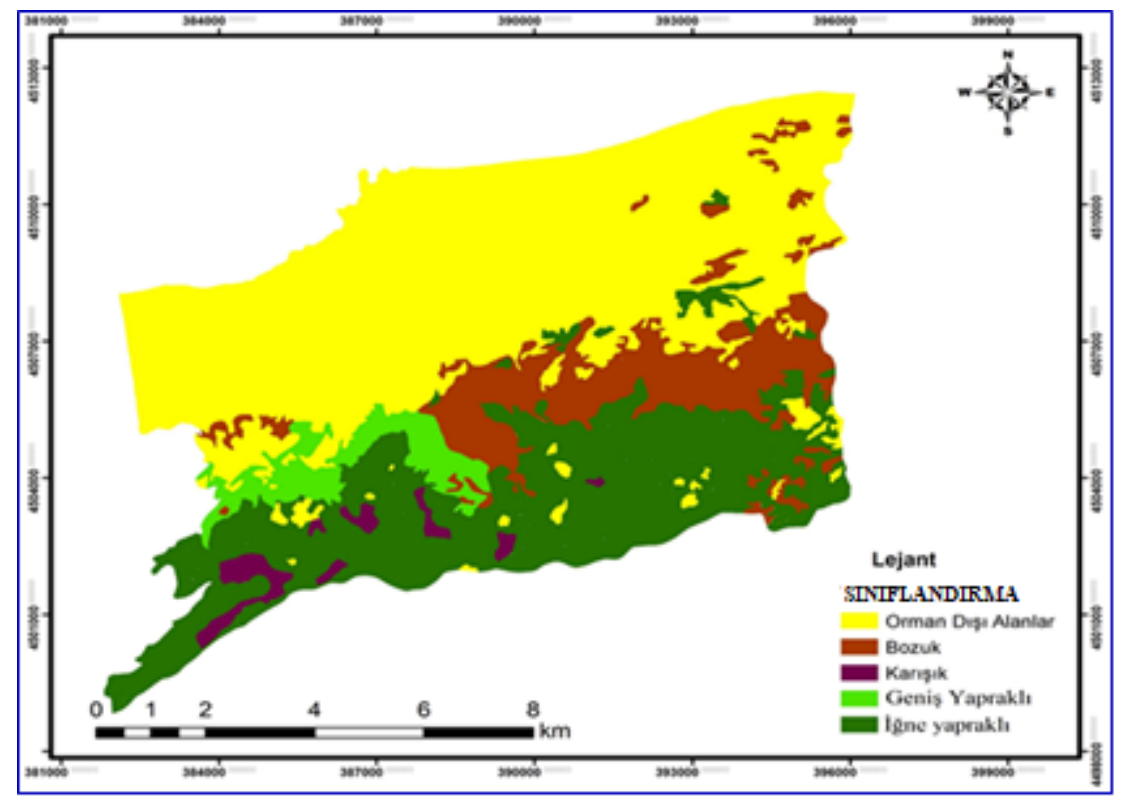

Şekil 2. Demirciler Orman İşletme Şefliği alansal dağılışı (1986-1995).

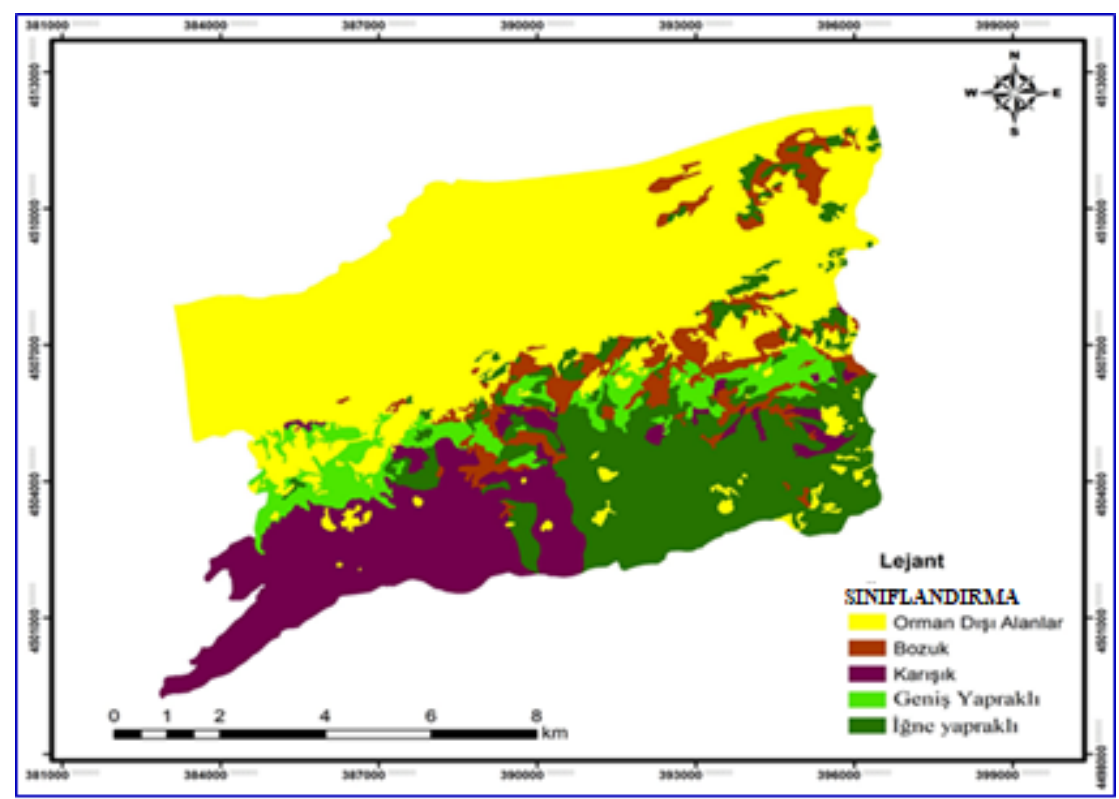

Şekil 3. Demirciler Orman İşletme Şefliği alansal dağılış1 (2009-2018).

\section{1. $A B D$ ve BEF Yöntemlerinin Karşılaştırılması}

ABD ve BEF Yöntemleri için hesaplamalar ve yaşanan değişimler ormancılıkta birim alan olarak kabul edilen hektar değerleri bazında hesaplanmış ve incelenmiştir. Demirciler plan ünitesi bazında; 1986 ve 2009 periyotlarında: ABD ve BEF yöntemiyle hesaplanmış olan iğne yapraklı, geniş yapraklı ve karışık meşcerelerde toprak altı ve toprak üstü tutulan biyokütle ve karbon değerleri Tablo 3 ve Tablo 4'de verilmiştir. 
Tablo 3. Demirciler OİŞ 1986-1995 periyodu için ABD ve BEF kullanılarak hesaplanan biyokütle ve karbon miktarları (ton/ha).

\begin{tabular}{llcccc}
\hline \multirow{2}{*}{1986} & & \multicolumn{2}{c}{ ABD } & \multicolumn{2}{c}{ BEF } \\
\cline { 3 - 6 } & & $\begin{array}{c}\text { Biyokütle } \\
\text { (ton/ha) }\end{array}$ & $\begin{array}{c}\text { Karbon } \\
\text { (ton/ha) }\end{array}$ & $\begin{array}{c}\text { Biyokütle } \\
\text { (ton/ha) }\end{array}$ & $\begin{array}{c}\text { Karbon } \\
\text { (ton/ha) }\end{array}$ \\
\hline \multirow{3}{*}{ Toprak Üstü } & İğne Yapraklı & 160,1 & 80,05 & 140,2 & 71,47 \\
& Geniş Yapraklı & 37,8 & 18,90 & 35,87 & 17,34 \\
& Karışı & 178,63 & 89,32 & 150,09 & 75,13 \\
\hline \multirow{2}{*}{ Toprak Altı } & İğne Yapraklı & 46,31 & 23,15 & 40,61 & 20,7 \\
& Geniş Yapraklı & 9,26 & 4.63 & 8,81 & 4,26 \\
& Karışı & 49,26 & 24,63 & 41,16 & 20,65 \\
\hline \multirow{3}{*}{ TOPLAM } & İğne Yapraklı & 206,4 & 103,2 & 180,81 & 92,18 \\
& Geniş Yapraklı & 47,06 & 23,53 & 44,68 & 21,6 \\
& Karışık & 227,89 & 113,94 & 191,25 & 95,78 \\
\hline
\end{tabular}

Demirciler 1986-1995 periyodunda ABD ile hesaplanan değerler kıyaslandığında; iğne yapraklı meşcerede toprak üstü biyokütle 160,10 ton/ha, karbon değeri ise 80,05 ton/ha'dır. Toprak üstü geniş yapraklı meşcerede hesaplanan biyokütle 37,80 ton/ha ve karbon değeri ise 18,90 ton/ha dır. Toprak üstü karışık meşcerede hesaplanan biyokütle 178,63 ton/ha ve karbon değeri ise 89,32 ton/ha dır. Toprak altı iğne yapraklı, geniş yapraklı, karışı meşcerelerde sırasıyla hesaplanan karbon değerleri; 21,74 ton/ha; 4,63 ton/ha ve 24,63 ton/ha olarak hesaplanmıştır.

Aynı plan döneminde BEF ile hesaplanan değerler incelendiğinde; toprak üstü iğne yapraklı meşcerede ile hesaplanan biyokütle değeri 140,20 ton/ha ve karbon değeri ise 71,47 ton/ha olarak hesaplanmıştır. Toprak üstü geniş yapraklı meşcerede hesaplanan biyokütle 35,87 ton/ha ve karbon değeri 17.34 ton/ha'dır. Toprak üstü karışık meşcerede hesaplanan biyokütle 150,09 ton/ha ve karbon değeri ise 75,13 ton/ha'dır. Toprak altı iğne yapraklı, geniş yapraklı, karışık meşcerelerde sırasıyla hesaplanan karbon değerleri 20,70 ton/ha, 4,26 ton/ha ve 20,65 ton/ha olarak hesaplanmıştır (Tablo 3).

İkinci plan dönemi olan 2009-2018 periyodu için ABD ile hesaplanan değerler Tablo 4'de verilmiştir. Tablo 4 incelendiğinde; toprak üstü iğne yapraklı, geniş yapraklı ve karışık meşcerelerde biyokütle değerleri sırasıyla 198,14 ton/ha; 114,28 ton/ha ve 151,08 ton/ha olduğu, karbon değerlerinin ise bu siralamayla 99,07 ton/ha; 57,14 ton/ha ve 75,54 ton/ha olduğu belirlenmiştir. Hesaplanan toprak altı karbon miktarları ise 28,57 ton/ha; 14,07 ton/ha ve 21,16 ton/ha'dir (Tablo4).

BEF ile yapılan hesaplamalarda ise toprak üstü iğne yapraklı meşcerede biyokütle değeri 187,07 ton/ha; karbon değeri ise 95,10 ton/ha'dır. Geniş yapraklı meşcerede biyokütle değeri 59,80 ton/ha; karbon değeri ise 30.59 ton/ha olurken, karış1k meşcerede hesaplanan biyokütle değeri 120,89 ton/ha ve karbon değeri ise 62,93 ton/ha olarak belirlenmiştir. Toprak altı iğne yapraklı, geniş yapraklı ve karışık meşcerelerde karbon değerleri sırasıyla; 23,43 ton/ha, 7,21 ton/ha ve 17,38 ton/ha'dır (Tablo4).

Tablo 4. Demirciler OİŞ 2009-2018 periyodu için ABD ve BEF kullanılarak hesaplanan biyokütle ve karbon miktarlar1.

\begin{tabular}{llcccc}
\hline \multirow{2}{*}{$2009-2018$} & & \multicolumn{2}{c}{ ABD } & \multicolumn{2}{c}{ BEF } \\
\cline { 3 - 6 } & & $\begin{array}{c}\text { Biyokütle } \\
\text { (ton/ha) }\end{array}$ & $\begin{array}{c}\text { Karbon } \\
\text { (ton/ha) }\end{array}$ & $\begin{array}{c}\text { Biyokütle } \\
\text { (ton/ha) }\end{array}$ & $\begin{array}{c}\text { Karbon } \\
\text { (ton/ha) }\end{array}$ \\
\hline \multirow{2}{*}{ Toprak Üstü } & İğne Yapraklı & 198,14 & 99,07 & 187,07 & 95,1 \\
& Geniş Yapraklı & 114,28 & 57,14 & 59,8 & 30,59 \\
& Karşsı & 151,08 & 75,54 & 120,89 & 62,93 \\
\hline \multirow{3}{*}{ Toprak Altı } & İğne Yapraklı & 57,13 & 28,57 & 46,06 & 23,43 \\
& Geniş Yapraklı & 28,13 & 14,07 & 14,84 & 7,21 \\
& Karışı & 42,32 & 21,16 & 34,3 & 17,38 \\
\hline \multirow{2}{*}{ TOPLAM } & İğne Yapraklı & 255,27 & 127,63 & 240,81 & 122,43 \\
& Geniş Yapraklı & 142,42 & 71,21 & 74,64 & 65,43 \\
& Karışı & 193,4 & 96,7 & 155,19 & 86,42 \\
\hline
\end{tabular}


Demirciler OİŞ'de 1986 ve 2009 yıllarına ait ABD ve BEF yöntemi ile hesaplanan toprak üstü-altı karbon ve biyokütle değerlerinde iğne yapraklı, geniş yapraklı ve karışık meşcerede yaşanan değişimler yüzde olarak hesaplanmıştır. ABD ile hesaplanan toprak üstü iğne yapraklı meşcerede biyokütle ve karbon değerlerinin 2009 yılında 1986 yılına göre \%23,76 arttığı görülmektedir. Geniş yapraklı meşcerede biyokütle ve karbon değerleri 2009 yılında 1986 yılına göre \% 202,33 artış ile oldukça yüksek bir oran vermektedir. Karışık meşcerelerde ise \%15,42 oranında azalma yaşandığı tespit edilmiştir. Her ne kadar karışık meşcere alansal olarak çok büyük oranda artış gösterse de ağırlıklı olarak genç meşcerelerden oluşması bu tezatlı̆̆ açıklamaktadır. Toprak altı biyokütle ve karbon değerinin 2009 yılında 1986 yılında göre değerinin \%23,39 arttığı görülmektedir. Geniş yapraklı meşcerede ABD ile hesaplanan toprak altı biyokütle ve karbon değerinin \%203,97 arttığı görülmektedir. Karışık meşcerede ABD ile hesaplanan toprak altı biyokütle ve karbon değerinin ise aynı dönemler arasında $\% 14.08$ oranında azaldığı görülmektedir (Tablo 5).

BEF ile hesaplanan toprak üstü iğne yapraklı meşcerede biyokütle miktarında 2009 yılında 1986 yılına göre \%33,42, karbon miktarında ise \%33,05 oranında artış olduğu belirlenmiştir. Geniş yapraklı meşcerelerde ise biyokütle miktarında \%66,68 oranına karşılık, karbon miktarında \%67,24 oranında artış olduğu tespit edilmiştir. BEF ile hesaplanan toprak üstü karışık meşcerede biyokütle değeri \%19,45 ve karbon değeri \%18,54 oranında azalış gösterdiği tespit edilmiştir. Toprak altı iğne yapraklı meşcerede 2009 yılında 1986 yılına göre biyokütle değerinin \%13,43 ve karbon değerinin \%13,16 arttığ meşcerede biyokütle değerinin \%68,50 ve karbon değerinin \%69,14 arttı̆̆ görülmektedir. BEF ile hesaplanan toprak altı karışık meşcerede biyokütle değerinin 1986 yılından 2009 yılına kadar \%16.68, karbon değerinin ise \%15.84 azaldığı görülmektedir (Tablo 5).

Tablo 5. Demirciler 1986-1995, 2009-2018 periyotlarına göre ABD ve BEF ile hesaplanan toprak üstü ve toprak altı biyokütle ve karbon miktarlarında meydana gelen değişimin yüzdesi.

\begin{tabular}{|c|c|c|c|c|c|c|c|c|}
\hline \multirow{3}{*}{ 1986-2009 } & \multicolumn{4}{|c|}{$\begin{array}{c}\text { Toprak Üstü Biyokütle ve Karbonun } \\
\text { Yıllara Göre Yüzde Değişimi }\end{array}$} & \multicolumn{4}{|c|}{$\begin{array}{c}\text { Toprak Altı Biyoküitle ve Karbon un } \\
\text { Yıllara Göre Yüzde Değişimi }\end{array}$} \\
\hline & \multicolumn{2}{|c|}{ ABD Yöntemi } & \multicolumn{2}{|c|}{ BEF Yöntemi } & \multicolumn{2}{|c|}{ ABD Yöntemi } & \multicolumn{2}{|c|}{ BEF Yöntemi } \\
\hline & $\begin{array}{l}\text { Biyokütle } \\
\%\end{array}$ & $\begin{array}{c}\text { Karbon } \\
\%\end{array}$ & $\begin{array}{c}\text { Biyokütle } \\
\%\end{array}$ & $\begin{array}{c}\text { Karbon } \\
\%\end{array}$ & $\begin{array}{l}\text { Biyokütle } \\
\%\end{array}$ & $\begin{array}{c}\text { Karbon } \\
\%\end{array}$ & $\begin{array}{l}\text { Biyokütle } \\
\%\end{array}$ & $\begin{array}{c}\text { Karbon } \\
\%\end{array}$ \\
\hline İğne Yapraklı & 23,76 & 23,76 & 33,42 & 33,05 & 23,38 & 23,39 & 13,43 & 13,16 \\
\hline Geniş Yapraklı & 202,33 & 202,33 & 66,68 & 67,24 & 203,97 & 203,97 & 68,5 & 69,14 \\
\hline Karışık & $-15,42$ & $-15,42$ & $-19,45$ & $-18,54$ & $-14,08$ & $-14,08$ & $-16,68$ & $-15,84$ \\
\hline
\end{tabular}

ABD ve BEF katsayıları kullanılarak hesaplanan karbon değerleri (ABD-BEF) arasında önemli farklılıklar vardır. Demirciler OİŞ 1986-2009 dönemindeki iğne yapraklı meşcerelerde yapılan hesaplamalarda ABD’e ait toprak üstü biyokütle ve karbon değerlerinin BEF’e göre sırasıyla \%14,19 ve \%12 oranında yüksek değerler verdiği görülmüştür (Tablo 6).

Tablo 6. Demirciler OİŞ için 1986-1995 ve 2009-2018 periyotlarındaki ABD İle Hesaplanan biyokütle ve karbon değerinin BEF'e göre yüzde fark1.

\begin{tabular}{llllll}
\hline & \multirow{2}{*}{ Plan Dönemi } & \multicolumn{2}{c}{$\begin{array}{c}\text { Toprak Üstü } \\
(\%)\end{array}$} & \multicolumn{2}{c}{$\begin{array}{c}\text { Toprak Altı } \\
\text { (\%) }\end{array}$} \\
\cline { 3 - 6 } & & Biyokütle & Karbon & Biyokütle & Karbon \\
\hline \multirow{2}{*}{ İğne Yapraklı } & $\mathbf{1 9 8 6 - 1 9 9 5}$ & 14,19 & 12 & 14,03 & 11,82 \\
& $\mathbf{2 0 0 9 - 2 0 1 8}$ & 5,92 & 4,18 & 24,03 & 21,92 \\
Geniş Yapraklı & $\mathbf{1 9 8 6 - 1 9 9 5}$ & 5,37 & 9 & 5,07 & 8,56 \\
& $\mathbf{2 0 0 9 - 2 0 1 8}$ & 91,12 & 97,06 & 89,54 & 95,1 \\
Karışık & $\mathbf{1 9 8 6 - 1 9 9 5}$ & 19,02 & 18,89 & 19,66 & 19,24 \\
\hline
\end{tabular}


2009-2018 plan döneminde bu değişimin biyokütlede \%5,92, karbon değerinde ise \%4,18 oranında ABD lehine olduğu görülmektedir. 1986-2009 periyodunda geniş yapraklı meşcerelerde ABD’ye ait toprak üstü biyokütle ve karbon değerleri BEF'e göre sırasıyla; \%5,37 ve \%9 fazla değer vermektedir. 2009-2018 plan döneminde ise ABD yöntemi BEF'le kıyaslandığında \%91,12 biyokütle hesabında, \%97,06 oranında ise karbon hesabında farklılık gösterdiği belirlenmiştir. Demirciler OİŞ 1986-2009 plan döneminde karışı meşcerelerde yapılan hesaplamalarda ABD'e ait toprak üstü biyokütle ve karbon değerleri BEF'e göre sirasıyla \%19,02 ve \%18,89 oranında değerler verdiği görülmüştür. 2009-2018 plan döneminde bu değişimin biyokütlede \%24,97, karbon değerinde ise \%23,44 olduğu görülmektedir (Tablo 6).

\section{Sonuç ve Öneriler}

Küresel iklim değişimi belirli bir bölge ya da coğrafyanın değil tüm dünya yaşamının geleceğini tehdit eden en önemli ekolojik sorundur. Bu sorunla mücadelede tüm dünyanın ortak hareket etmesi gerekmektedir. Küresel iklim değişikliğinin etkisinin azaltılmasında karasal ekosistemlerden orman ekosistemlerinin önemli olduğu gerçeğinden hareketle, ormanlarda biriken karbonun gerçeğe en yakın şekilde belirlenmesi gereklidir. Orman ekosisteminin depoladığı karbon miktarı ve bunun yıllık değişimleri toprak üstü biyokütle, toprak altı biyokütle, ölü odun, ölü örtü ve organik toprak olmak üzere 5 başlık altında değerlendirilmektedir.

Çalışmada iki farklı yöntemle hesaplamalar yapılarak sonuçlar elde edilmiş ve değerlendirilmiştir. ABD yöntemi ağaç biyokütle denklemlerine, BEF yöntemi ise servete bağlı olarak hesaplamaları gerçekleştirmektedir. ABD yöntemi BEF’e kıyasla daha yüksek sonuçlar vermiştir (Şekil 4).

1986-1995 Plan Dönemi

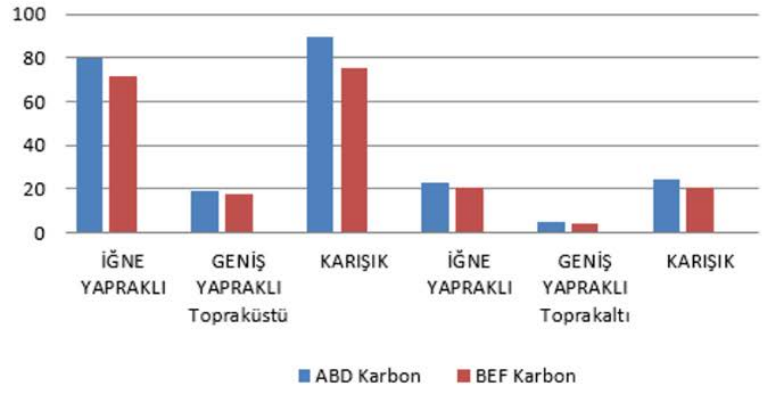

2009-2018 Plan Dönemi

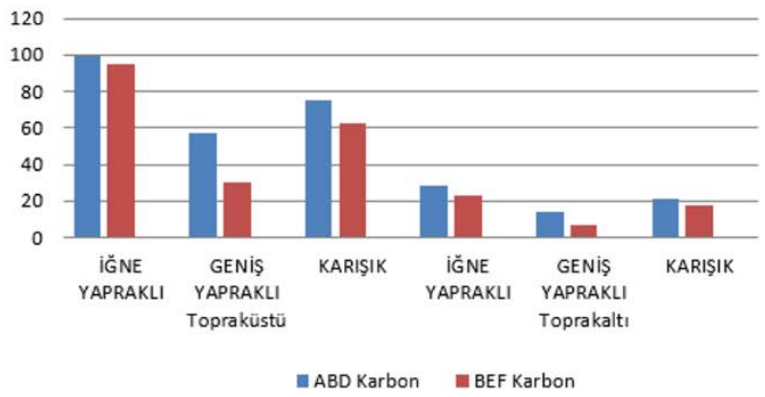

Şekil 4. Demirciler OİŞ için plan dönemlerine göre ABD ve BEF değerleri.

Çalışmada 1986-1995 ve 2009-2018 plan döneminde meşcere tiplerine göre karbon miktarı haritaları oluşturulmuştur (Şekil 5). Karbon miktarı haritalarda 0-30, 30-60, 60-90, 90-120 ve 120 ton/ha üstü olmak üzere beş ayrı sınıfta gösterilmiştir. İki yöntem kıyaslandı̆̆ında 1986-1995 plan döneminde BEF yöntemiyle hesaplanan değerleri gösteren karbon haritasında 30-60 ve 60-90 arasındaki değer fazla, ABD yönteminde bu değerler azken 90-120 arasındaki değerler yüksek çıkmıştır. 2009-2018 plan döneminde BEF yöntemi sonucuna dayanan karbon haritasında 0-30, 30-60 ve 60-90 sınıfları arasındaki değerler fazla, ABD yönteminde ise daha az, 90-120 ve 120 üstü değerleri ise daha yüksek çıkmıştır.

Demirciler OİŞ'de yapılan bu çalışmanın 1985-1995 plan dönemine ait ABD ve BEF yöntemi hesaplamaları sonucunda elde edilen karbon miktarları Durkaya ve ark. (2017) tarafından yapılan çalışmanın sonuçlarıyla karşılaştırılmıştır. Durkaya ve ark. (2017) 1985-1995 plan döneminde iğne yapraklı ormanlardan oluşan Sarıalan OIŞ’ de iğne yapraklılarda toprak üstü karbon miktarını 60,39 ton/ha, toprak altı karbon miktarını ise 17,51 ton/ha olarak hesaplamışlardır. Demirciler OİŞ’nin iğne yapraklılarda toprak üstü karbon miktarı ise 71,47 ton/ha, toprak altı karbon miktarı da 20,70 ton/ha olarak hesaplanmıştır. Sarıalan OİŞ'de ABD yöntemiyle iğne yapraklılarda toprak üstü karbon miktarı 63,97 ton/ha, toprak altı karbon miktarı ise 18,55 ton/ha çıkmıştır. Demirciler OİŞ'de ise iğne yapraklılarda toprak üstü karbon miktarı 80,05 ton/ha ve toprak altı karbon miktarı 23,15 ton/ha çıkmıştır. $1.700 \mathrm{~m}$ ile $1.950 \mathrm{~m}$ yükseklikleri arasında yer alan Sarıalan OİŞ’nin iğne yapraklı ormanlık alanı 3.735,50 ha, $750 \mathrm{~m}$ ile $1.150 \mathrm{~m}$ yükseklikleri arasında yer alan Demirciler OİŞ’nin ise 2.972,5 ha'dır (Anon, 1986). Karbon miktarlarında görülen farkın meşcere tiplerinin gelişim çağları ve yetişme ortamından kaynaklandığ 1 düşünülmektedir. 


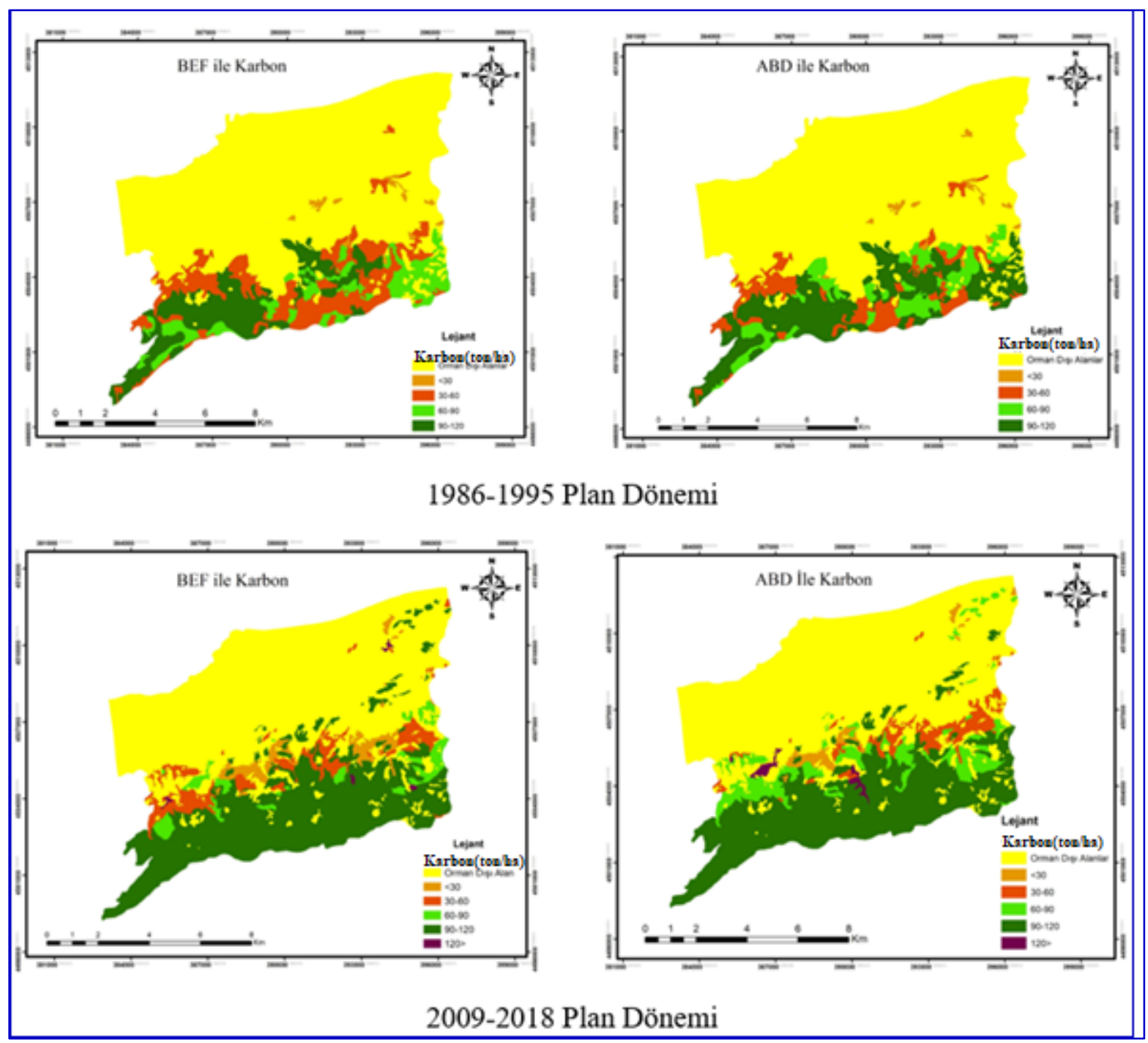

Şekil 5. Demirciler OİŞ’nin plan dönemlerindeki hektarda karbon değişimi(ton/ha).

Her coğrafi bölgesinde farklı iklim özellikleri gösteren Türkiye’nin küresel iklim değişikliğinden farklı şekilde etkilenme göstermesi beklenmektedir. Ayrıca Türkiye'nin Kyoto Protokolü, Paris Anlaşması gibi uluslararası anlaşmalar gereğince bugün olmasa bile yakın gelecekte karbon piyasasında üzerine düşen sorumlulukları yerine getirebilmesi için mevcut karbon stoklarını en doğru ve sağlıklı şekilde belirlemesi gereklidir.

Yapılan bu çalışmada Allometrik Biyokütle Denklemleri (ABD) ve Biyokütle Genişletme Faktörlerinden (BEF) yararlanarak karbon miktarı hesaplaması yapılmıştır. Orman biyokütlesi hesabı yapılırken genelde meşcere biyokütlesine yoğunlaşılmaktadır. Son yıllara kadar, yapılan çalışmalarda toprak altı biyokütle ihmal edilerek, toprak üstünden toprak altına dönüşümler yapılarak hesaplamalar gerçekleştirilmekteydi. ABD yöntemleri ile yapılan çalışmalar son 20 yıllık dönem içerisinde toprak altı biyokütle denklemlerinin de çalışmalarda ortaya konulduğu görülmektedir. Ağaç türleri ve yetişme ortamlarına özgü geliştirilen toprak altı ve toprak üstü biyokütle denklemleri kullanımının daha doğru sonuçlar vereceği düşünülmektedir. Bu çalışma sonucunda, karbon depolama miktarının hesaplanmasında kullanılan yöntemler arasından gerçeğe daha yakın değerlere ulaşmak için her ağaç türüne ait kendi biyokütle denklemlerinin kullanılması gerektiği söylenebilir. Türkiye'de geliştirilen her ağaç türüne göre allometrik denklemlerin olmaması karbon depolama miktarlarının tam olarak hesaplanmasında yetersiz kalmaktadır. Bu yüzden her ağaç türüne göre allometrik denklem oluşturularak karbon depolama miktarlarının daha gerçekçi hesaplanması sağlanmalıdır. Özellikle geniş yapraklı türlerin biyokütle denklemlerinin olmaması ise ABD yönteminin bir eksikliği olarak düşünülebilir. Karbon depolama kapasitesinin yanında ormana yapılan silvikültürel müdahalelerin karbon depolama kapasitesini nasıl ve ne yönde etkilediği, ayrıca fonksiyonlarına göre işletilen sahaların birbirine kıyasla ne kadar karbon depolama kapasitesine sahip olduğunu gösteren çalışmalar da yapılmalıdır. 


\section{Teşekkür}

Bartın Üniversitesi'nde Doç. Dr. Birsen DURKAYA danışmanlığında Melih KOCAMAN tarafından hazırlanmış olan yüksek lisans tezinden türetilen bu çalışma, BAP-2018-FEN-CY-002 numarasıyla desteklenmiştir. Desteklerinden dolayı Bartın Üniversitesi’ne teşekkür ederiz.

\section{Kaynaklar}

1. Anon (1986). Orman Genel Müdürlüğü, Bolu Orman Bölge Müdürlüğü, Bolu Orman İşletme Müdürlügü̈, Demirciler Orman İşletme Şefliği Orman Amenajman Planı 1986-1995.

2. Anon, (2009). Orman Genel Müdürlüğü, Bolu Orman Bölge Müdürlüğü, Aladağ Orman İşletme Müdürlüğü, Demirciler Orman İşletme Şefliği Orman Amenajman Planı 2009-2018.

3. Asan, Ü. (1995). Global iklim değişimi ve Türkiye ormanlarında karbon birikimi. İstanbul Üniversitesi Orman Fakültesi Dergisi, 45(1-2), 23-38.

4. Asan, Ü., Destan, S., Özkan, U. Y. (2002). İstanbul korularının karbon depolama, oksijen üretimi ve toz tutma kapasitesinin kestirilmesi. Orman Amenajamanında Kavramsal Açılımlar ve Yeni Hedefler Sempozyumu, Bildiriler Kitabı, İstanbul, Türkiye, 194-202.

5. Backéus, S., Wikström, P., Lämås, T. (2005). A model for regional analysis of carbon sequestration and timber production. Forest Ecology and Management, 216(1-3), 28-40.

6. Baker, J. S., Wade, C. M., Sohngen, B. L., Ohrel, S., Fawcett, A. A. (2019). Potential complementarity between forest carbon sequestration incentives and biomass energy expansion. Energy Policy, 126, 391401.

7. Brown, S. (2002). Measuring carbon in forests: current status and future challenges. Environmental Pollution, 116(3), 363-372.

8. Chave, J., Andalo, C., Brown, S., Cairns, M. A., Chambers, J. Q., Eamus, D., ... \& Lescure, J. P. (2005). Tree allometry and improved estimation of carbon stocks and balance in tropical forests. Oecologia, 145(1), 87-99.

9. Chave, J., Réjou-Méchain, M., Búrquez, A., Chidumayo, E., Colgan, M. S., Delitti, W. B., ..., Henry, M. (2014). Improved allometric models to estimate the aboveground biomass of tropical trees. Global Change Biology, 20(10), 3177-3190.

10. Coomes, D. A., Allen, R. B., Scott, N. A., Goulding, C., Beets, P. (2002). Designing systems to monitor carbon stocks in forests and shrublands. Forest Ecology and Management, 164(1-3), 89-108.

11. Dewar, R. C., Cannell, M. G. (1992). Carbon sequestration in the trees, products and soils of forest plantations: an analysis using UK examples. Tree Physiology, 11(1), 49-71.

12. Dhakal, B., Kattel, R. R. (2019). Effects of global changes on ecosystems services of multiple natural resources in mountain agricultural landscapes. Science of the Total Environment, 676, 665-682.

13. Durkaya, B. (1998). Zonguldak Orman Bölge Müdürlüğü Meşe Meşcerelerinin Biyokütle Tablolarının Düzenlenmesi. Yüksek Lisans Tezi, Zonguldak Karaelmas Üniversitesi, Fen Bilimleri Enstitüsü, 110.

14. Durkaya, A., Durkaya, B., Çakıl, E. (2009b). Predicting the above-ground biomass of crimean pine (Pinus nigra )stands in Turkey. Journal of Environmental Biology, 31, 115-118.

15. Durkaya, A., Durkaya, B., Ünsal, A. (2009a). Predicting the above-ground biomass of calabrian pine (Pinus brutia Ten.) stands in Turkey. African Journal of Biotechnology, Vol 8 (11), 2483-2488 ISSN 16845315 (c) 2009 Academic Journals.

16. Durkaya, A., Durkaya, B., Atmaca, S. (2010). Predicting the Above-ground Biomass of Scots Pine (Pinus sylvestris L.) Stands in Turkey. Energy Sources, Part A, 32, 485-493, DOI:10.1080/15567030802612473.

17. Durkaya, B., Durkaya, A., Makineci, E., Karabürk, T. (2013b). Estimating Above-Ground B1omass and Carbon Stock of Individual Trees in Uneven-Aged Uludag Fir Stands. Fresenius Environmental Bulletin, 22 (2), 428-434.

18. Durkaya, B., Durkaya, A., Makineci, E., Ülküdür,M. (2013a). Estimation of Above-Ground Biomass and sequestered Carbon of Taurus Cedar (Cedrus libani L.) in Antalya, Turkey. iForest-Biogeosciences and Forestry. 6:278-284. DOI:10.3832/ifor0899-006.

19. Durkaya, B., Varol, T., \& Durkaya, A. (2014). Determination of carbon stock changes: Biomass models or biomass expansion factors.

20. Durkaya, B. , Durkaya, A. , Kocaman M. , (2017). Karbon Stok Değişimi; Bolu Sarıalan İşletme Şefliği Örneği, Bartın Orman Fakültesi Dergisi, : 19(1): 268-275 Cilt 19, Sayı 1.

21. Gençay, G., Birben, Ü., Durkaya, B. (2018). Effects of legal regulations on land use change: 2/B applications in Turkish forest law. Journal Of Sustainable Forestry, 37(8), 804-819.

22. Elias, M., Potvin, C. (2003). Assessing inter-and intra-specific variation in trunk carbon concentration for 32 neotropical tree species. Canadian Journal of Forest Research, 33(6), 1039-1045. 
23. Fang, J. Y., Wang, G. G., Liu, G. H., Xu, S. L. (1998). Forest biomass of China: an estimate based on the biomass-volume relationship. Ecological Applications, 8(4), 1084-1091.

24. Fang, J., Guo, Z., Piao, S., \& Chen, A. (2007). Terrestrial vegetation carbon sinks in China, 1981-2000. Science in China Series D: Earth Sciences, 50(9), 1341-1350.

25. Fearnside, P. M. (1985). Environmental change and deforestation in the Brazilian Amazon. Change in the Amazon Basin: Man's Impact on Forests and Rivers, 70-89.

26. FRA (2010). Country Report, Turkey, pp.37-39.

27. Fukuda, M., Iehara, T., Matsumoto, M. (2003). Carbon stock estimates for sugi and hinoki forests in Japan. Forest Ecology And Management, 184(1-3), 1-16.

28. Gower, S. T., Kucharik, C. J., Norman, J. M., (1999). Direct and indirect estimation of leaf area index, F(APAR), and net primary production of terrestrial ecosystems. Remote Sensing of Environment,70, 2951.

29. Hashimotio, T., Kojima, K., Tanşe, T., Satohiko, S., (2000). Changes in carbon storage in fallow forests in the tropical lowlands of Borneo. Forest Ecology and Management, 126: 331-337.

30. Huxley, D. J., Huxley, J. S. (1993). Problems of relative growth. The Johns Hopkins Unıversity Press. Baltimore and London.

31. IPCC (2003). Good practice guidance for land use, land-use change and forestry. Institute for Global Environmental Strategies (IGES), Hayama, Japan.

32. IPCC (2006). IPCC Guidelines for National Greenhouse Gas Inventories, Prepared by the National Greenhouse Gas Inventories Programme. In: Eggleston, H.S., Buendia, L., Miwa, K., Ngara, T., Tanabe, K. (Eds.). IGES, Japan. Available at: http://www.ipcc-nggip.iges.or.jp/public/2006gl/index.html [Verified 29/10/ 2008].

33. IPCC (2013). Summary for Policymakers. In: Climate Change 2013: The Physical Science Basis. Contribution of Working Group I to the Fifth Assessment Report of the Intergovernmental Panel on Climate Change [Stocker, T.F., D. Qin, G.-K. Plattner, M. Tignor, S.K. Allen, J. Boschung, A. Nauels, Y. Xia, V. Bex and P.M. Midgley Cambridge, United Kingdom and New York, USA.

34. İkinci, O. (2000). Bolu Orman Bölge Müdürlüğü Kestane Meşcerelerinin Biyokütle Tablolarının Düzenlenmesi, ZKÜ Fen Bilimleri Enstitüsü, Yüksek Lisans Tezi, 86 s.

35. Jandl, R., Lindner, M., Vesterdal, L., Bauwens, B., Baritz, R., Hagedorn, F., ..., Byrne, K. A. (2007). How strongly can forest management influence soil carbon sequestration?. Geoderma, 137(3-4), 253-268.

36. Kangas, A., Maltamo, M. (Eds.). (2006). Forest inventory: methodology and applications (Vol. 10). Springer Science \& Business Media.

37. Ketterings, Q.M., Coe, R., van Noordwijk, M., Ambaşau, Y. \& Palm, C.A., (2001). Reducing uncertainty in the use of allometric biomass equations for predicting above-ground tree biomass in mixed secondary forests. Forest Ecology and Management,146: 199-209.

38. Laiho, R., Laine, J. (1997). Tree stand biomass and carbon content in an age sequence of drained pine mires in southern Finland. Forest Ecology and Management, 93(1-2), 161-169.

39. Lamlom, S. H., Savidge, R. A. (2003). A reassessment of carbon content in wood: variation within and between 41 North American species. Biomass and Bioenergy, 25(4), 381-388.

40. Leonard, B., Costello, C., Libecap, G. D. (2019). Expanding Water Markets in the Western United States: Barriers and Lessons from Other Natural Resource Markets. Review of Environmental Economics and Policy, 13(1), 43-61.

41. Matthews, H. D., Gillett, N. P., Stott, P. A., Zickfeld, K. (2009). The proportionality of global warming to cumulative carbon emissions. Nature, 459(7248), 829-832.

42. Matthews, H. D., Zickfeld, K., Knutti, R., Allen, M. R. (2018). Focus on cumulative emissions, global carbon budgets and the implications for climate mitigation targets. Environmental Research Letters, 13(1), 010201.

43. Milne, R., Brown, T. A. W., Murray, T. D. (1998). The effect of geographical variation of planting rate on the uptake of carbon by new forests of Great Britain. Forestry: An International Journal of Forest Research, 71(4), 297-309.

44. Niklas, K. J., Enquist, B. J. (2001). Invariant scaling relationships for interspecific plant biomass production rates and body size. Proceedings of the National Academy of Sciences, 98(5), 2922-2927.

45. Niklas, K. J., Owens, T., Reich, P. B., Cobb, E. D. (2005). Nitrogen/phosphorus leaf stoichiometry and the scaling of plant growth. Ecology Letters, 8(6), 636-642.

46. OGM (2014). Ekosistem Tabanlı Fonksiyonel Orman Amenajmanı Planlarının Düzenlenmesine Ait Usul ve Esaslar. OGM.

47. Olalekan, R. M., Omidiji, A. O., Williams, E. A., Christianah, M. B., Modupe, O. (2019). The roles of all tiers of government and development partners in environmental conservation of natural resource: a case study in Nigeria. MOJ Ecology \& Environmental Sciences, 4(3), 114-121. 
48. Pajtík, J., Konôpka, B., Lukac, M. (2008). Biomass functions and expansion factors in young Norway spruce (Picea abies [L.] Karst) trees. Forest Ecology and Management, 256(5), 1096-1103.

49. Paul, K. I., Roxburgh, S. H., Chave, J., England, J. R., Zerihun, A., Specht, A., ..., Huxtable, D. (2016). Testing the generality of above-ground biomass allometry across plant functional types at the continent scale. Global Change Biology, 22(6), 2106-2124.

50. Porté, A., Trichet, P., Bert, D., Loustau, D. (2002). Allometric relationships for branch and tree woody biomass of Maritime pine (Pinus pinaster Ait.). Forest Ecology and Management, 158(1-3), 71-83.

51. Saraçoğlu, N. (1998). Kayın (Fagus orientalis Lipsky) Biyokütle Tabloları, Tr. J. of Agriculture and Forestry, 22, pp 93-100.

52. Schoene, D. (2002). Terminology in assessing and reporting forest carbon change. In Second expert meeting on harmonizing forest-related definitions for use by various stakeholders. FAO, Rome.

53. Schroeder, P., Brown, S., Mo, J., Birdsey, R., Cieszewski, C. (1997). Biomass estimation for temperate broadleaf forests of the United States using inventory data. Forest Science, 43(3), 424-434.

54. Schulp, C. J., Nabuurs, G. J., Verburg, P. H., de Waal, R. W. (2008). Effect of tree species on carbon stocks in forest floor and mineral soil and implications for soil carbon inventories. Forest Ecology and Management, 256(3), 482-490.

55. Shi, L., Liu, S. (2017). Methods of Estimating Forest Biomass: A Review. In Biomass Volume Estimation and Valorization for Energy. InTech.

56. Somogyi, Z., Cienciala, E., Mäkipää, R., Muukkonen, P., Lehtonen, A., Weiss, P. (2007). Indirect methods of large-scale forest biomass estimation. European Journal of Forest Research, 126(2), 197-207.

57. Tobin, B., Nieuwenhuis, M. (2007). Biomass expansion factors for Sitka spruce (Picea sitchensis (Bong.) Carr.) in Ireland. European Journal of Forest Research, 126(2), 189-196.

58. Tolunay, D., Çömez, A. (2008). Türkiye ormanlarinda toprak ve ölü örtüde depolanmiş organik karbon miktarlari. Hava Kirliliği ve Kontrolü Ulusal Sempozyumu Bildiri Kitab1, s.750-765. 22-25 Ekim 2008, Hatay.

59. Tolunay, D. (2011). Total carbon stocks and carbon accumulation in living tree biomass in forest ecosystems of Turkey. Turkish Journal of Agriculture and Forestry, 35(3), 265-279.

60. Tolunay, D. (2012). Türkiye'de ağaç servetinden bitkisel kütle ve karbon miktarlarının hesaplamasında kullanılabilecek katsayılar. Ormancılıkta Sektörel Planlamanın 50. Y11ı Uluslararası Sempozyumu Bildiriler Kitabı, s:240-251 Ankara, 2013.

61. UN (1992). United Nations Framework Convention on Climate Change. United Nations, Fccc/Informal/84, Ge. 05-62220.

62. Usuga, J. C. L., Toro, J. A. R., Alzate, M. V. R., Tapias, Á. D. J. L. (2010). Estimation of biomass and carbon stocks in plants, soil and forest floor in different tropical forests. Forest Ecology and Management, 260(10), 1906-1913.

63. Van Camp, N., Walle, I. V., Mertens, J., De Neve, S., Samson, R., Lust, N., ..., Mestdagh, I. (2004). Inventory-based carbon stock of Flemish forests: a comparison of European biomass expansion factors. Annals of Forest Science, 61(7), 677-682.

64. Vashum, K. T., Jayakumar, S., (2012). Methods to Estimate Above-Ground Biomass and Carbon Stock in Natural Forests - A Review, J Ecosyst Ecogr 2012, 2:4 http://dx.doi.org/10.4172/2157-7625.1000116.

65. Wang, C. (2006). Biomass allometric equations for 10 co-occurring tree species in Chinese temperate forests. Forest Ecology and Management, 222(1-3), 9-16.

66. Woodwell, G. M., Whittaker, R. H., Reiners, W. A., Likens, G. E., Delwiche, C. C., Botkin, D. B. (1978). The biota and the world carbon budget. Science, 199(4325), 141-146.

67. Yolasığmaz, H., Çavdar, B., Demirci, U., Aydın, İ. (2016). İki farklı yönteme göre karbon birikiminin tahmin edilmesi: Artvin Orman İşletme Şefliği örneği. Türkiye Ormancılık Dergisi, 17(1), 43-51.

68. Zhang, X., Wang, M., Liang, X. (2008). Quantitative classification and carbon density of the forest vegetation in Lüliang Mountains of China. In Forest Ecology (pp. 1-9). Springer, Dordrecht.

69. Zickfeld, K., Eby, M., Matthews, H. D., Weaver, A. J. (2009). Setting cumulative emissions targets to reduce the risk of dangerous climate change. Proceedings of the National Academy of Sciences, 106(38), 16129-16134. 